\title{
A probabilistic inverse method for volcanic ash dispersion modelling
}

\author{
M. J. Zidikheri ${ }^{1} \quad$ R. Potts ${ }^{2} \quad$ C. Lucas $^{3}$
}

(Received 6 March 2015; revised 11 November 2015)

\begin{abstract}
We present a new inverse modelling approach for integrating satellite detections of volcanic ash with dispersion models. We demonstrate the utility of this approach in estimating the ash column height in the February 2014 eruption of Mount Kelut in Java, Indonesia. We show that the inferred height is consistent with estimates obtained by other remote sensing techniques. This method may be used to obtain estimates of model parameters such as ash column height in cases where no such information is available or is subject to significant uncertainty.
\end{abstract}

http://journal.austms.org.au/ojs/index.php/ANZIAMJ/article/view/9384 gives this article, (c) Austral. Mathematical Soc. 2016. Published January 3, 2016, as part of the Proceedings of the 17th Biennial Computational Techniques and Applications Conference. ISSN 1446-8735. (Print two pages per sheet of paper.) Copies of this article must not be made otherwise available on the internet; instead link directly to this URL for this article. 


\section{Contents}

1 Introduction

C195

2 Inverse modelling strategy

C197

3 February 2014 Kelut eruption

C198

4 Inverse modelling results

C202

5 Conclusion

C206

References

C207

\section{Introduction}

Ash emitted from volcanic eruptions poses a significant hazard to aviation, mainly due to its deleterious effects on aircraft engines [1]. The monitoring and forecasting of ash during volcanic eruptions is required in order to manage this risk. The Australian Bureau of Meteorology operates the Darwin Volcanic Ash Advisory Centre (VAAC) which provides warnings to aviation stakeholders over a region that includes Australia, Indonesia, and Papua New Guinea.

Dispersion modelling is the main tool used for forecasting the transport of ash in the atmosphere. Lagrangian dispersion models such as HYSPLIT (hybrid single particle Lagrangian integrated trajectory) [2], which is used operationally by the Darwin VAAC, calculate the trajectories of particles emitted by the eruption, driven by gridded wind fields and sub-grid turbulence. A key issue in the use of dispersion models is the description of the source function, which is a representation of the processes that inject the ash into the atmosphere, specifically its spatial (and perhaps temporal) form. Currently, the operational practice is to assume a line source extending from the volcano summit to a specified maximum altitude. Remote sensing using the MTSAT 
geostationary satellite is the principal means by which ash is detected in the atmosphere. However, there are significant uncertainties in the detection of volcanic ash [3]. Moreover, even when ash is successfully detected, there are still significant challenges in estimating ash properties such as altitude and column loadings [4]. In view of these challenges, it is crucial to integrate the dispersion model simulations with satellite retrievals in order to gain a more coherent picture of the transport of ash. Data assimilation, as this procedure is generally known, has a long history in meteorology, but it is only relatively recently that such approaches have been attempted in volcanic ash dispersion modelling. Several studies investigated the problem of reconstructing ash and $\mathrm{SO}_{2}$ emission profiles associated with recent eruption events $[5,6,7]$.

In this article we demonstrate how information about ash location obtained from satellite data is combined with information from dispersion models to yield improved estimates of the spatial form of the source function, particularly its vertical structure (i.e., the emission profile), using inverse modelling. Our method differs in some respects from the method used in the aforementioned studies $[5,6,7]$. Rather than attempting to reconstruct the emission profile in detail, we specify a general form that is dependent on only a few parameters. For example, we focus on a cylindrical source in which the only adjustable parameter is the top altitude (the ash column height). We then form a parameter grid consisting of possible top altitude values and perform a systematic grid search by running several dispersion model simulations for each point on the parameter grid. The dispersion model simulations are compared against observations in the form of satellite retrievals by using pattern correlations from which optimal parameter values are then obtained. This avoids some of the difficulties associated with other inverse modelling approaches, such as negative emission rates, which have to be corrected in an ad hoc fashion. The other point of difference is that our approach is inherently probabilistic (although a strictly deterministic scheme is also investigated and will be discussed further in this article). The uncertainty is built into the system by selecting a set of optimal values with similar values of pattern correlations. Section 4 shows that this makes the system more robust to 
model and observation errors.

\section{Inverse modelling strategy}

Let the vector $\mathbf{d}$ represent a set of observations such as mass column loading (i.e., vertically integrated concentration) at various gridded locations and let $\mathbf{g}(\mathbf{m})$ represent the corresponding gridded model outputs which are dependent on the choice of model parameters $\mathbf{m}$. Here, $\mathbf{m}$ represents the height of the ash column but in general it could represent other parameters related to the source term such its base altitude, diameter, and eruption duration, each of which would be represented as a component of $\mathbf{m}$. We formulate the inverse problem as that of finding the values of $\mathbf{m}$ that maximise the pattern correlation

$$
r(m)=\frac{d^{\prime} \cdot g^{\prime}(m)}{\left\|d^{\prime}\right\|\left\|g^{\prime}(m)\right\|}
$$

where the prime symbols denote deviations from mean quantities; that is, $\mathbf{d}^{\prime}=\mathbf{d}-\overline{\mathrm{d}} \mathbf{1}$ and $\mathbf{g}^{\prime}(\mathbf{m})=\mathbf{g}(\mathbf{m})-\overline{\mathbf{g}}(\mathbf{m}) \mathbf{1}$ with mean values $\overline{\mathrm{d}}=\mathbf{1} \cdot \mathbf{d} / \mathbf{1} \cdot \mathbf{1}$ and $\overline{\mathbf{g}}(\mathbf{m})=\mathbf{1} \cdot \mathbf{g}(\mathbf{m}) / \mathbf{1} \cdot \mathbf{1}$. Here, the dot operator denotes the scalar product of two vectors and $\mathbf{1}$ is a vector with all components equal to one. To solve the inverse problem we must find the values of $\mathbf{m}$ that maximize the pattern correlation $\mathbf{r}(\mathbf{m})$, as this implies maximum alignment of the vectors $\mathbf{d}^{\prime}$ and $\mathbf{g}^{\prime}$. The magnitudes of the vectors do not influence the results and this makes equation (1) a particularly convenient measure of agreement between model and observations when the spatial patterns are in arbitrary units. This is frequently the case because it is still difficult to estimate ash concentrations, as noted in Section 1.

The pattern correlation in equation (1) is maximised by systematically searching the parameter space formed by all possible vectors $\boldsymbol{m}$. This is accomplished by specifying upper and lower limits for each component of $\mathbf{m}$ and subdividing the resulting range into $\mathrm{N}$ equally spaced values to form $\mathrm{N}^{\mathrm{n}}$ grid points, where $\mathrm{n}$ is the number of components of $\mathbf{m}$. The number of components $\mathrm{n}$ cannot 
be too large due to the exponential growth of the number of grid points in this method. Dispersion model simulations with parameter values defined at each of these grid points are run, and resulting column loading values are compared with satellite-derived ash column loading values by using the pattern correlation measure in equation (1).

We investigate two different inversion schemes, namely deterministic and probabilistic. In the deterministic scheme, which is more suited for situations in which there is high confidence in the satellite retrievals and dispersion model performance, the vector $\mathbf{m}$ yielding the highest pattern correlation is chosen as the solution of the inverse problem. In the probabilistic scheme, parameters satisfying

$$
\frac{r(m)}{R} \geqslant \alpha
$$

are chosen to form the solution ensemble. Here $r$ is the pattern correlation value at some parameter grid point, $\mathbf{m}$, and $R$ is the maximum pattern correlation value. If the cut-off parameter $\alpha$ is chosen to be one, then the probabilistic scheme reduces to the deterministic scheme. However, generally we shall choose $\alpha$ to be about 0.95 , a choice we justify empirically in subsequent sections. Because of the inherent uncertainties in satellite retrieved ash mass loading values, we only compare the simulated and observed (satellite retrieved) ash distribution fields in binary form; that is, we only consider whether a given location contains ash or not, and not the absolute ash mass loading value. Ash probability distributions are calculated by taking the average value of the binary valued ( 0 or 1 ) ash loading field at every (longitude, latitude) grid point in the solution ensemble.

\section{February 2014 Kelut eruption}

Mount Kelut located in Java, Indonesia (7.93S 112.31E, summit elevation $1731 \mathrm{~m}$ ) erupted for several hours starting at around 1600 UTC on February 13, 2014 . From the standpoint of our research, this eruption is important due 
to the abundance of satellite data associated with the eruption. Here we make use of two of such data sets, namely those from the MTSAT-2 [8] and CALIPSO [9] satellite instruments. MTSAT-2 is a geostationary satellite which provides continuous coverage of a fixed area on the globe; this area includes the region of interest, namely the Indonesian region. MTSAT- 2 data is available operationally once every hour. The first MTSAT- 2 image after the eruption was available at 1630 UTC, about half an hour after the start of the eruption.

Figure 1 shows the 1830 UTC infrared $(11 \mu \mathrm{m})$ brightness temperature (BT) image. The temperatures associated with the cold anomaly are below $195 \mathrm{~K}$ which correspond to altitudes of around $16 \mathrm{~km}$ using vertical profile information available at around that time from the nearby Surabaya station. This altitude is the approximate altitude of the tropopause which separates the troposphere from the stratosphere above; this effectively acts as a lid inhibiting upward motion of tropospheric particles such as volcanic ash. However, also noticeable in this image is a warmer region with temperatures above $200 \mathrm{~K}$ embedded within the cold anomaly. This is evidence of stratospheric intrusion of ash due to the strength of this particular eruption. This is confirmed by Figure 2, obtained from the CALIPSO satellite-borne lidar instrument at around 1830 UTC.

CALIPSO provides information about the vertical structure of the ash, and Figure 2 shows that the ash extends to over $25 \mathrm{~km}$, well into the stratosphere. CALIPSO travels in a polar orbit and superposed on Figure 1 is its orbital track in the vicinity of the volcano. Figure 2 shows that the broader region of ash extending up to about $19 \mathrm{~km}$ corresponds to the colder temperatures (white areas) in Figure 1. This broad region is generally referred to as an umbrella cloud, due to shape of the eruption column which tends to be narrow at lower altitudes and broad at higher (around tropopause) altitudes. The CALIPSO image clearly indicates that the umbrella cloud extends above the tropopause (in addition to the aforementioned narrow stratospheric intrusion region). The BT based height estimates assume that the ash is a perfect black body, which is a reasonable assumption for the optically dense umbrella cloud region near the tropopause. This assumption is less likely to be valid for the 
Figure 1: MTSAT-2 infrared brightness temperature (K) with ash identified by cold anomaly (white area).
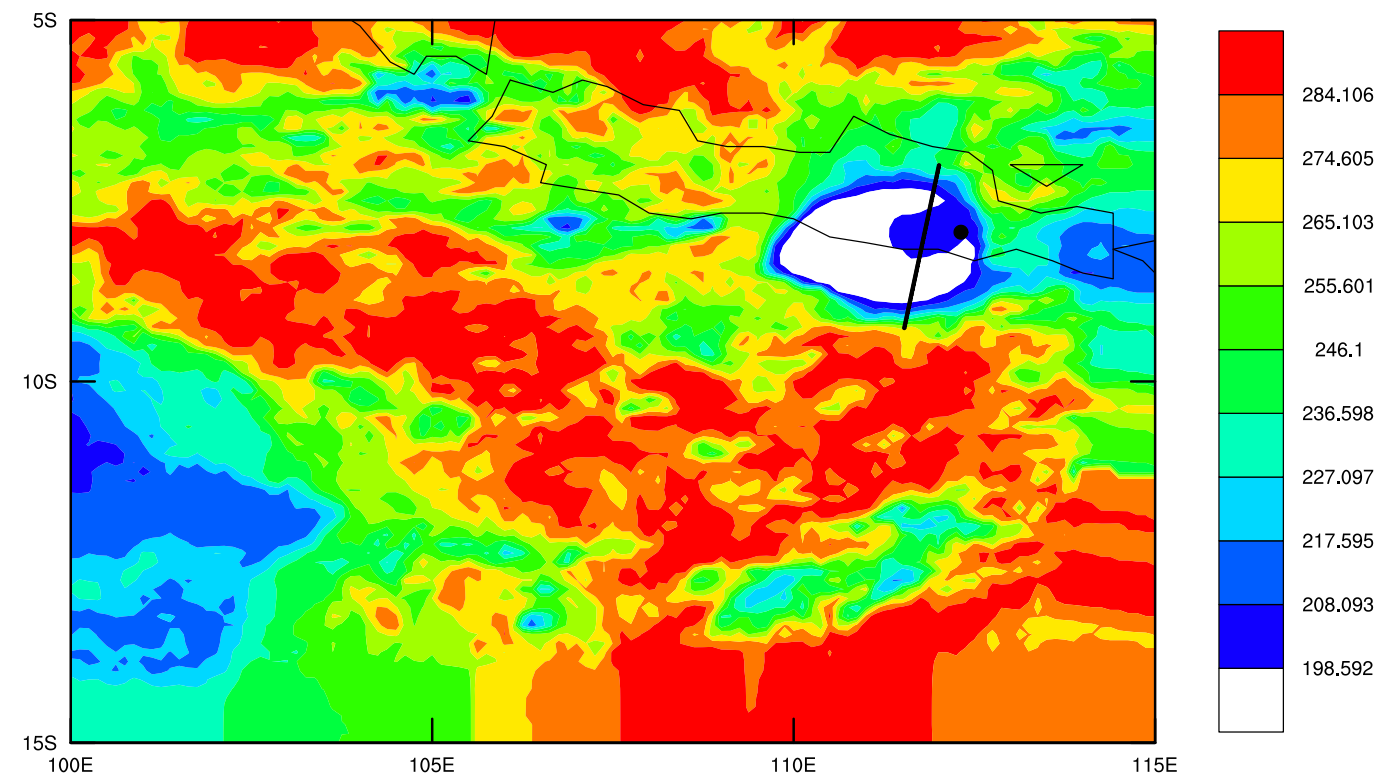

ash in the stratosphere and therefore the BT based height estimates are less likely to be accurate there.

As described in Section 2, for the purposes of inverse modelling we are only interested in demarcating areas that contain ash from areas not containing ash and therefore we introduce a cut-off temperature chosen from an examination of the imagery (the final results were found to be relatively insensitive to the precise value of this cut-off temperature) in the vicinity of the volcano. This cut-off was used to create a binary representation of the ash cloud and used as the observational data in the inverse model. A similar procedure can be applied to the BT images at other times. As the plume moves away from the volcano it generally becomes more difficult to demarcate it from the surrounding meteorological clouds using the BT image and the associated retrieval is therefore more prone to error. Additionally, the BT images do not 
Figure 2: CALIPSO image with vertical structure of ash shown in yellow. The span of the base of the yellow region corresponds to the span of the orbital track shown in Figure 1.

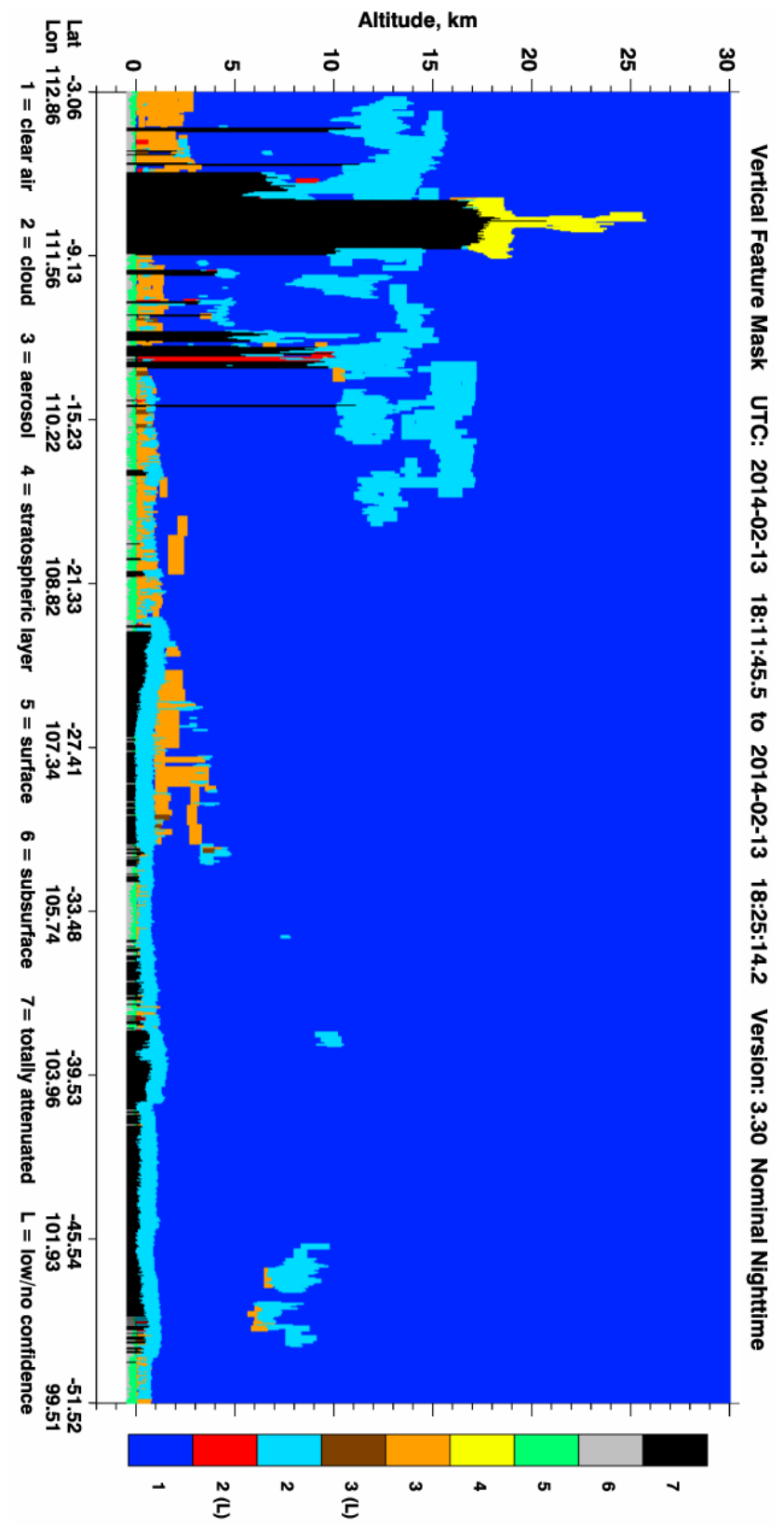


capture the ash at lower altitudes due to the presence of water/ice clouds. In such situations ash is detected by other methods such the brightness difference temperature method [10] and the algorithm of Pavolonis [11]. Ash was only detected by these methods from about 1930 UTC. Moreover, the very optically thick part of the cloud was not detected by these methods until some time later. However, unlike in the BT images, ash was identified at lower altitudes and it is therefore useful to combine information from these two detections. This was done from 1930 UTC onwards.

\section{Inverse modelling results}

Here we evaluate to what extent the algorithm described in Section 2 can be used to infer the maximum vertical extent of the ash column by using MTSAT- 2 satellite data only. Ash profile information from CALIPSO will only be used to verify the estimates obtained from the inverse model because CALIPSO, unlike MTSAT-2, does not provide continuous real-time coverage over a fixed area of the globe and cannot therefore be used on a systematic basis for operational data assimilation. HYSPLIT is used to model the transport of ash. The model employs a cylindrical ash source from which particles are released. The base of the cylinder is fixed at the volcano summit altitude of $1.7 \mathrm{~km}$ while the top $(h)$ is treated as a variable to be optimised with respect to ash observations at hourly intervals between 1630 and 2130 UTC. The diameter of the source is chosen to be $100 \mathrm{~km}$, taking into account the size of the umbrella cloud seen in imagery at 1630 UTC. The particle release time is specified to be 1600 uTC and the eruption duration to be 4 hours. The source top altitude is initially specified to be somewhere in the range $10-30 \mathrm{~km}$.

The results are summarised in Table 1. From Table 1, the optimal maximum altitude of the ash column is at or above $20 \mathrm{~km}$, using observations within the first six hours from the start of the eruption. The range of values satisfying equation (2) is also shown in Table 1 . We see that the inferred possible values are all above $17 \mathrm{~km}$ to a maximum of $29 \mathrm{~km}$, with the exception of $1630 \mathrm{UTC}$ 
Table 1: Top altitude of ash column ( $h$ ) as inferred by inverse modelling at different time steps. The maximal and minimal values refer to the range of possible values obtained from the inversion.

\begin{tabular}{lcccc} 
Time UTC & optimal $\mathrm{h}(\mathrm{km})$ & $\mathrm{r}$ & minimal $\mathrm{h}(\mathrm{km})$ & maximal $\mathrm{h}(\mathrm{km})$ \\
\hline 1630 & 24.0 & 0.77 & 14.0 & 29.0 \\
1730 & 23.0 & 0.73 & 17.0 & 29.0 \\
1830 & 22.0 & 0.71 & 18.0 & 29.0 \\
1930 & 20.0 & 0.77 & 19.0 & 29.0 \\
2030 & 21.0 & 0.78 & 18.0 & 29.0 \\
2130 & 23.0 & 0.77 & 18.0 & 29.0
\end{tabular}

which yields possible altitudes above $14 \mathrm{~km}$. These ranges are consistent with the observed maximal extent of the ash column shown in Figure 2. Optimal altitude values at each observation time are in the range $20-24 \mathrm{~km}$ with the observed value of around $25 \mathrm{~km}$ being just outside this range.

Figure 3 shows the variation of the pattern correlation $r$, with $h$ at 1830 UTC. We understand from this figure why the inferred range of possible values of $h$ is quite wide $(18-29 \mathrm{~km})$. The reason is that the pattern correlation curve becomes flat at about $\mathrm{h}=18 \mathrm{~km}$ or so. A similar behaviour is observed at other observation times, with the possible exception of 1630 UTC (not shown) in which the flat region appears at lower altitudes. The explanation for this flatness is that the wind patterns are such that in the simulation it becomes difficult to discriminate between transport of ash at altitudes higher than $18 \mathrm{~km}$. The red line in Figure 3 shows the discrete probability distribution function calculated from equation (2). Simulations employing values of $h$ satisfying this relationship are given weights of one within the solution ensemble while those with values of $h$ not satisfying this relationship are given weights of zero. With the chosen value of the cut-off parameter, $\alpha=$ 0.95 , this weighting has the effect of only retaining simulations with values of $h$ within the flat part of the pattern correlation curve.

The solution ensemble is integrated forward in time to yield probabilistic 
Figure 3: Variation of pattern correlation (scaled to a maximum value of one) with ash source top altitude (black) and corresponding discrete probability distribution function (red) obtained using observations at 1830 UTC.

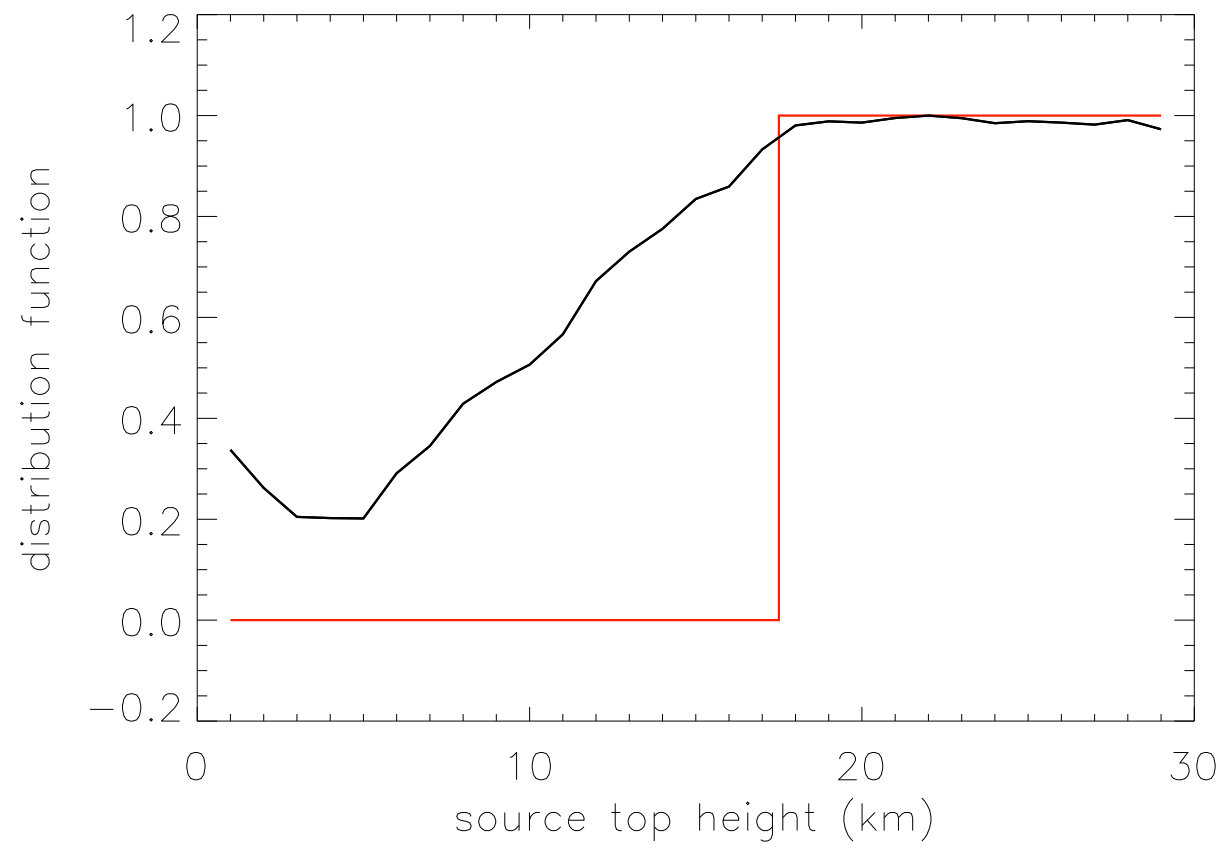

forecasts of ash. Figure 4 shows the ash forecasts at 14/0630 UTC (i.e., 12 hours later) based on both the deterministic version of the model (using the optimal value $h=22 \mathrm{~km}$ ) and the probabilistic version (using the range $18 \mathrm{~km} \leqslant \mathrm{~h} \leqslant 29 \mathrm{~km}$ ). It is fortunate that around this time another CALIPSO overpass was available which showed ash at around $17-20 \mathrm{~km}$. The CALIPSO track is shown in both plots in Figure 4. Both deterministic and probabilistic forecasts clearly predict ash at the location of the CALIPSO track. Additionally, regions identified as containing ash by the MTSAT-2 satellite using the algorithm of Pavolonis [11] are shown in Figure 4. These are also in good agreement with the forecasts, although clearly there are regions predicted to have ash by the dispersion model but which are not predicted by the 
Figure 4: Ash bearing locations at 14/0630 UTC obtained from analysis at 13/1830 UTC for (top) the deterministic forcast (shown in red) and (bottom) the probabilistic forecast (probabilities shown in colour bar). The CALIPSO (straight dotted line) and MTSAT-2 (dotted curve) satellite detections of ash at around this time are also shown.

\section{DETERMINISTIC}
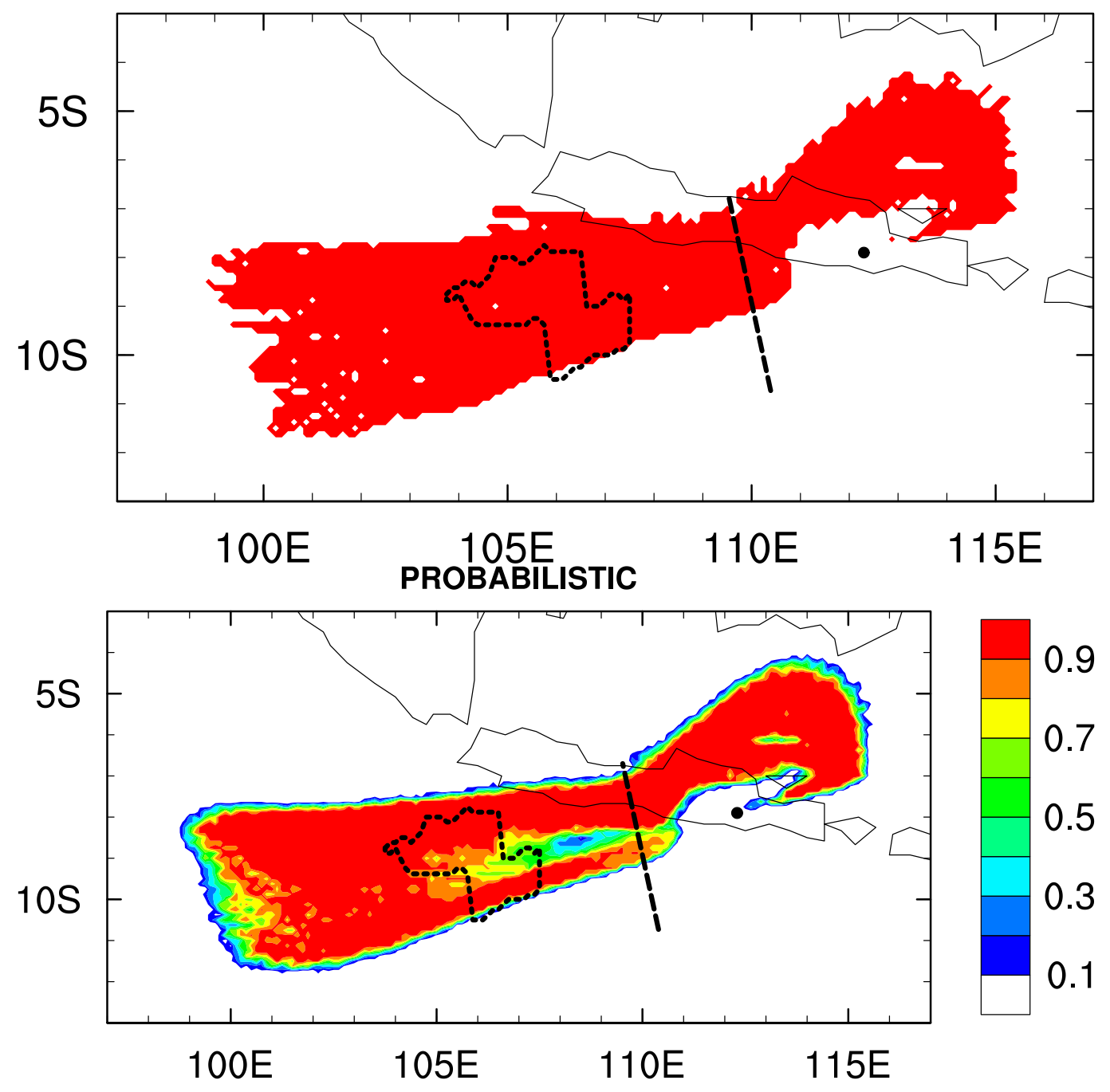
Pavolonis algorithm. The main difference between the forecasts is that the probabilistic forecast predicts two main separate westward branches with high probability, and lower probability in the areas in between, whereas the deterministic forecast predicts ash everywhere.

\section{Conclusion}

We presented a new method for inferring optimal dispersion model parameters from observations of volcanic ash obtained from satellite data. The method uses pattern correlations to compare a suite of simulations with different model parameters against observations. In the deterministic variant the model parameters that yield the maximum pattern correlation are chosen as the solution and used to issue forecasts of ash transport. In the probabilistic variant the model parameters yielding pattern correlations greater than a specified cut-off parameter are chosen to form the ensemble of the solutions from which probabilistic forecasts are issued. The latter approach takes into account that both the model and the observations contain errors that might mask the true solution. Additionally, the wind structure might be such that the true solution is difficult to untangle from other candidate solutions.

We tested this method using the February 2014 Kelut eruption in Java, Indonesia, mainly because of the availability of corroborating lidar (CALIPSO) observations associated with this event. We focussed on a particular problem, namely that of determining the maximum altitude of the ash column at the location of the volcano, which is a one parameter problem. This height was determined by CALIPSO to be about $25 \mathrm{~km}$, consistent with an analysis of infrared BT imagery. Depending on the observation time, the inverse method yielded estimates of $20-24 \mathrm{~km}$ in the deterministic scheme while, in the probabilistic scheme, values between $17-29 \mathrm{~km}$ were obtained from 1730 UTC onwards. This method may therefore be used to obtain height estimates in situations where the commonly used BT method does not work as well, such as for optically thin clouds. Additionally, the method can also 
be used to infer other model parameters not easily obtained by other means such as the horizontal span of the umbrella cloud and the mean particle size of ash particles in the cloud. These applications will be considered in future publications.

\section{References}

[1] Casadevall, T. J., (Ed) Volcanic ash and aviation safety; proceedings of the First international symposium on Volcanic ash and aviation safety. U.S. Geological Survey, 1994. http://pubs.er.usgs.gov/publication/b2047 C195

[2] Draxler, R. R., and Hess, G. D., An overview of the HYSPLiT4 modelling system for trajectories. Aust. Met. Mag. 47(4):295-308, 1998. http://www.bom.gov . au/amm/papers . php?year=1998 C195

[3] Simpson, J. J., Hufford, G., Pieri, D., and Berg, J., Failures in detecting volcanic ash from a satellite-based technique. Remote Sens. Environ. 72(2):191-217, 2000. doi:10.1016/S0034-4257(99)00103-0 C196

[4] Webster, H. N., Thomson, D. J., Johnson, B. T., Heard, I. P. C., Turnbull, K., Marenco, F., Kristiansen, N. I., Dorsey, J., Minikin, A., Weinzierl, B., Schumann, U., Sparks, R. S. J., Loughlin, S. C., Hort, M. C., Leadbetter, S. J., Devenish, B. J., Manning, A. J., Witham, C. S., Haywood, J. M., and Golding, B. W., Operational prediction of ash concentrations in the distal volcanic cloud from the 2010 Eyjafjallajökull eruption. J. Geophys. Res.-Atmos. 117(D20), 2012. doi:10.1029/2011JD016790 C196

[5] Eckhardt, S., Prata, A. J., Seibert, P., Stebel, K., and Stohl, A., Estimation of the vertical profile of sulfur dioxide injection into the atmosphere by a volcanic eruption using satellite column measurements 
and inverse transport modeling. Atmos. Chem. Phys. 8(14):3881-3897, 2008. doi:10.5194/acp-8-3881-2008 C196

[6] Kristiansen, N. I., Stohl, A., Prata, A. J., Richter, A., Eckhardt, S., Seibert, P., Hoffmann, A., Ritter, C., Bitar, L., Duck, T. J., and Stebel, K., Remote sensing and inverse transport modeling of the Kasatochi eruption sulfur dioxide cloud. J. Geophys. Res.-Atmos., 115(D2), 2010. doi:10.1029/2009JD013286 C196

[7] Stohl, A., Prata, A. J., Eckhardt, S., Clarisse, L., Durant, A. , Henne, S., Kristiansen, N. I., Minikin, A., Schumann, U., Seibert, P., Stebel, K., Thomas, H. E., Thorsteinsson, T., Torseth, K., and Weinzierl, B., Determination of time-and height-resolved volcanic ash emissions and their use for quantitative ash dispersion modeling: the 2010 Eyjafjallajökull eruption. Atmos. Chem. Phys. 11(9):4333-4351, 2011. doi:10.5194/acp-11-4333-2011 C196

[8] Ohkawara, N, Multifunctional transport satellite (MTSAT). Technical Report. Meteorological Satellite Center, Japan Meteorological Agency, Japan http://citeseerx.ist.psu.edu/viewdoc/download?doi=10. 1.1.4.8950\&rep=rep1\&type=pdf C199

[9] Winker, D. M., Pelon, J. R., and McCormick, M. P, The CALIPSO mission: spaceborne lidar for observation of aerosols and clouds. Proc. SPIE 4893, Lidar Remote Sensing for Industry and Environment Monitoring III, 4893:1-11, 2003. doi:10.1117/12.466539 C199

[10] Prata, A. J., Infrared radiative transfer calculations for volcanic ash clouds Geophys. Res. Lett. 16(11):1293-1296, 1989. doi:10.1029/GL016i011p01293 C202

[11] Pavolonis, M. J., Heidinger, A. K., and Sieglaff, J. Automated retrievals of volcanic ash and dust cloud properties from upwelling infrared measurements. J. Geophys. Res.-Atmos. 118(3):1436-1458, 2013. doi:10.1002/jgrd.50173 C202, C204 


\section{Author addresses}

1. M. J. Zidikheri, Australian Bureau of Meteorology, GPO Box 1289, Melbourne, Victoria 3001, Australia.

mailto:m.zidikheri@bom.gov.au

2. R. Potts, Australian Bureau of Meteorology, GPO Box 1289, Melbourne, Victoria 3001, Australia.

3. C. Lucas, Australian Bureau of Meteorology, GPO Box 1289, Melbourne, Victoria 3001, Australia. 